(1)

George Fox

UNIVERSITY
Digital Commons @ George Fox University

Faculty Publications - Graduate School of Counseling

Graduate School of Counseling

7-2020

Using the Post-Traumatic Growth Model to Explore Trauma

Narratives in Group Work with African Refugee Youth

Hannah E. Acquaye

Carol M. John

Laurie A. Bloomquist

Nicole M. Milne

Follow this and additional works at: https://digitalcommons.georgefox.edu/gsc

Part of the Counseling Commons 


\title{
Using the Post-Traumatic Growth Model to Explore Trauma Narratives in Group Work with African Refugee Youth
}

\author{
Hannah E. Acquaye , Carol M. John, Laurie A. Bloomquist, and Nicole M. Milne \\ Western Seminary
}

\begin{abstract}
African American youth and African refugee youth encounter systemic racism in similar yet different ways. Because of the inherent traumatic experiences encountered by refugee youth, the added discrimination during their acculturation processes elevates their trauma and stressor-related symptoms. This paper uses the Posttraumatic Growth Model to explore some steps in facilitating an 8-week group therapy for African refugee youth in the US school system. Culturally-sensitive recommendations are also provided.
\end{abstract}

\section{KEYWORDS}

Posttraumatic growth; refugee youth; group counseling; psychodrama

The construct of posttraumatic growth (PTG; Tedeschi \& Calhoun, 1996) operates from a strength-based framework in addressing mental wellness (Antonovsky, 1993; Calhoun et al., 2010), contrary to the pathogenetic framework which focuses on illness causing factors. Growth after adversity has been explored since antiquity, however, scientific study of the health benefits of growth after adversity is still an emerging area of study (Tedeschi \& Calhoun, 2004). With the advent of positive psychology, research has exploded with constructs such as happiness (Seligman, 2002), optimism (Carver \& Scheier, 2002), resilience (Bonanno, 2004), and posttraumatic growth (Tedeschi \& Calhoun, 1996). Collectively, these constructs focus on positivity instead of negativity when clients experience adversity.

Post Traumatic Growth (PTG), specifically, focuses on a person's perception and experience of psychological growth following adversity that disrupts their worldview (Calhoun \& Tedeschi, 2014). Growth, or positive psychological change, stems from responses in the aftermath of a traumatic experience, not from the trauma itself (Tedeschi \& Calhoun, 2004).

Although PTG and resilience are commonly used interchangeably, they are distinct from one another. The disruption of worldview is critical in understanding this distinction. It is not a necessary condition for resilience, a trait that allows a person to bounce back to their previous level of functioning after adversity (Taku \& Cann, 2014). However, without a disruption of worldview, there is no PTG or "bouncing forward", a phenomenon indicating advancement and replanting. Various researchers argue that resilient individuals cannot gain posttraumatic growth (Taku \& Cann, 2014); others posit that people can bounce back and forward, making it possible for resilience and PTG to coexist (Johnson et al., 2007); yet some insist that not all traumatic experiences lead to PTG (Tedeschi \& Calhoun, 2004). Although both constructs describe positive changes in the face of adversity, PTG contains 
a more significant transformative potential. An unsettled worldview creates a struggle whereby a person grows in their appreciation of life, relationships with others, envisioning new possibilities, personal strength and spiritual understanding (see Acquaye, Sivo et al., 2018; Calhoun \& Tedeschi, 2014).

\section{Posttraumatic Growth and Refugees}

The PTG model (see Figure 1) describes the stages that individuals may go through as they navigate their traumatic experiences. According to the model, a seismic event like tribal war or ethnic cleansing will occur for an individual to change from his or her pre-trauma position. The events could plunge the person into various challenges. For refugee youth, such challenges may include hypervigilance, sleeplessness, startle responses, or reckless

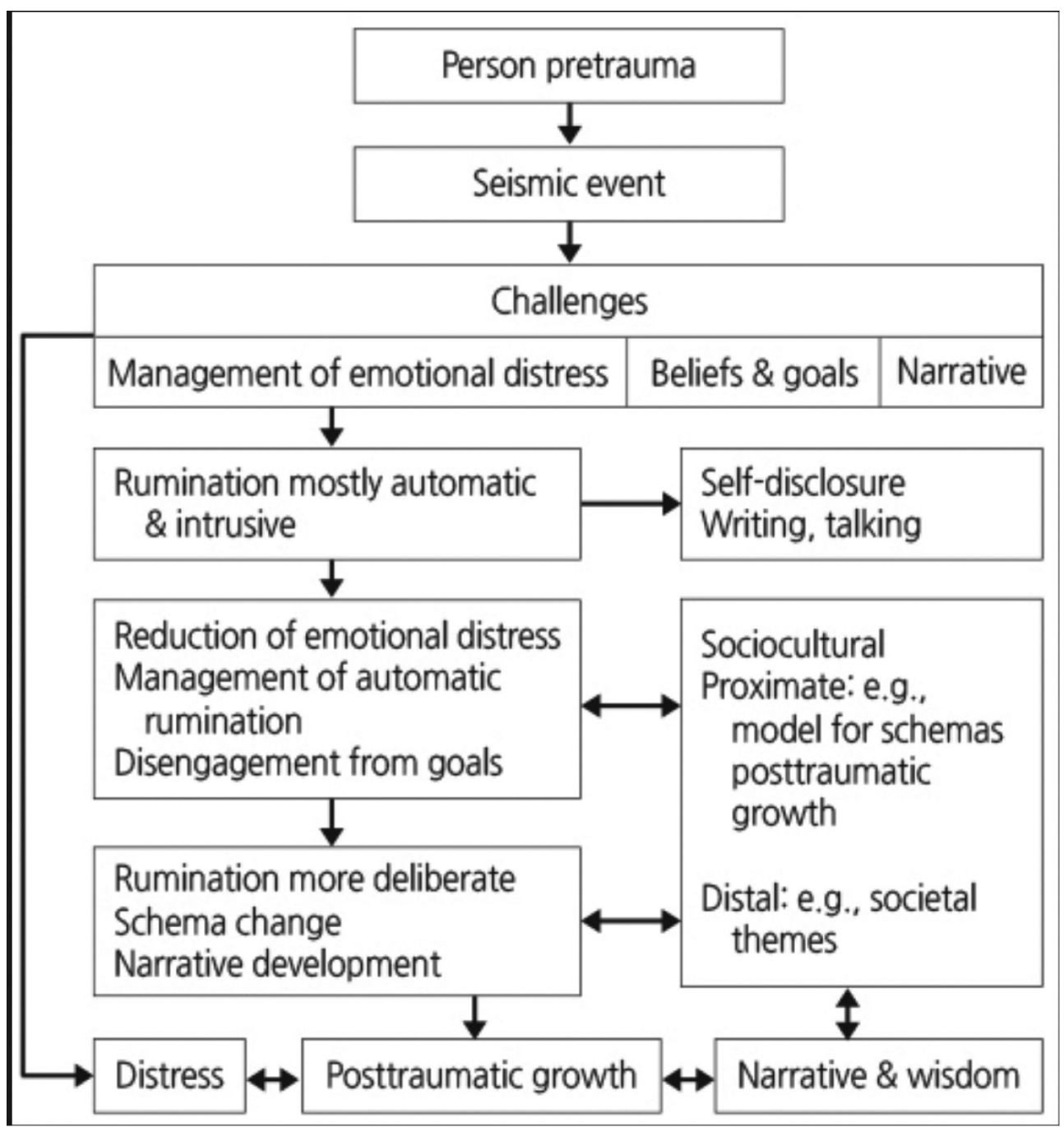

Figure 1. A model of posttraumatic growth (based on Calhoun et al., 2010). 
behaviors. These challenges require people to manage their emotional distress as they grapple with their core beliefs and goals, and often change their life narrative. People at this stage tend to exhibit characteristics that classify them as having trauma related symptoms (American Psychiatric Association, 2013). Refugees may engage in automatic and intrusive rumination (American Psychiatric Association, 2013), and may therefore need their socio-cultural context to help manage these automatic ruminations and reduce their emotional distress.

A study involving African former refugees examined the ability of religious commitment to moderate the effect of trauma on PTG (Acquaye, Sivo, et al., 2018). The results of the study indicated that although religious commitment alone was able to predict PTG to a great degree, it had a curvilinear moderating effect on growth. This means that when former refugees had some level of religious commitment, they showed increased PTG scores, in contrast to high religious commitment scores predicting low PTG scores. Another study on African refugees used path analysis to explore the role of trauma and optimism in PTG (Acquaye, Mitchell et al., 2018). Results of this study identified statistically significant correlations among war experiences, optimism, and growth, with no correlation between war experiences and optimism. The writers concluded that if counselors are able to enhance optimism within their refugee clients, they stand a higher chance of gaining psychological growth through their war-related traumatic experiences.

Other studies on refugees have focused on resettled youth in North America (Jani \& Reisch, 2017; Marshall et al., 2016; Patel et al., 2017) and have addressed narratives of this sample as they navigate their new homes. The Marshall study (Marshall et al., 2016) explored the challenges refugee youth deal with regularly, and how these challenges impede their mental wellness. The researchers concluded that despite these challenges, refugee youth demonstrated an ability to adapt and persevere in their new homes. The authors encouraged mental health workers to acknowledge the strengths of this population. The Patel study (Patel et al., 2017) explored the differences in trauma symptoms for war-related refugee youth and immigrant youth not exposed to war. Teachers in the Patel study confirmed that in war-exposed refugee youth, more than their non-war-exposed counterparts, there was an increase in anxiety-related symptoms, behavior problems, and a decrease in achievement scores. The youth themselves confirmed these assertions by their teachers. However, acculturative stressors predicted only self-reported anxiety symptoms, lower academic achievement and conduct problems for adolescents who had not been exposed to war.

Betancourt and her colleagues studied refugee youth who were once child soldiers $(N=243$; Betancourt et al., 2014). The researchers examined social disorder, collective efficacy within the community, perceived stigma, and externalizing and internalizing symptoms among former child soldiers in Sierra Leone. Even though there was no significant relationship between collective efficacy and mental health outcomes, social disorder and perceived stigma positively co-varied with participants' externalizing and internalizing behaviors. The Betancourt study (Betancourt et al., 2014) sheds some light on the intersectionality between post-conflict social context and mental health among former child soldiers who may themselves have become refugees. The similarity between the Betancourt study (Betancourt et al., 2014) and the Acquaye studies (Acquaye, Mitchell, et al., 2018; Acquaye, Sivo, et al., 2018) is that these refugees returned to their home country - a process known as repatriation by the United Nations High Commissioner for Refugees (UNHCR). While the Acquaye studies 
(Acquaye, Mitchell, et al., 2018; Acquaye, Sivo, et al., 2018) focused on adult victims, the Betancourt study (Betancourt et al., 2014) focused on youth. The Marshall study, like the Betancourt study, focused on youth. The former, though, examined the experiences of youth who were refugees in another country, while the latter explored the experiences of youth who had repatriated to their home country. Naturally, these youth encountered different experiences in navigating social and cultural systems based on their location - one in their home country and the other in a new more economically advanced country.

\section{African Refugee Youth in the US - Challenges and Strengths}

The studies described above add to the United Nations' (UN) growing concerns about an upsurge in displacement in recent years. According to the UN, 20 people are forcibly displaced each minute because of conflict or persecution, 65.6 million people are displaced worldwide, 22.5 million of these are refugees, and more than half of these are children under 18 years old (www.unhcr.org). Africa and the Middle East host about $56 \%$ of all refugees, while North America (United States and Canada) hosts about 16\%. In 2017, the US Department of state reported the resettlement of 53,716 refugees in the US (http://www.unhcr.org/en-us/resettle ment-in-the-united-states.html). Forty percent of these refugees were from the Near East and South Asia, followed by 37\% from Africa. The top five states who hosted these refugees were California, Texas, New York, Washington, and Ohio.

Many refugees report fleeing conflict and persecution. They might feel hopeful when they receive documents for resettlement in the United States (US), but most face challenges beyond their expectations upon settlement (Acquaye, 2017; International Counseling and Community Services, 2015). Refugee youth from Africa face additional challenges. Given their physical appearance, they encounter systemic racism that the average African American youth has had to navigate their whole life (Goodrum et al., 2015). For the first time in the lives of many African refugee youth, they are a minority, subject to overt and covert racism in the US. Refugee youth, especially from Africa, have the added burden of spending most of their adolescence in refugee camps, thereby making it difficult for them to fit into the academic level of their age mates in the host country (MacNevin, 2012). The stress related to not finding a place in school intensifies the mental health challenges they already face in navigating their new country.

Most refugee youth are further required to study in a second language, sometimes, with no previous knowledge of English. Many of them do not have previous education which supports their transition to the American school system (MacNevin, 2012). The American school curriculum fails to properly support refugee youth during their adjustment to a new culture and context. Many youth may feel that their culture or experience is irrelevant in this new system. In this way, what is currently happening to African refugee youth is no different from what happened to Native American youth who were forced into boarding schools and made to speak only English, thereby relegating their language and customs to irrelevant or nonexistent aspects of their personhood (Sue \& Sue, 2016). To mitigate some of these curriculum-related challenges, some researchers have suggested an incorporation of language-learning technology as well as open-minded discussion of refugee issues discussions that allow students of the dominant culture to have insight into world events, resulting in a reduction in negative and stereotypical attitudes toward refugees (MacNevin, 2012; Woods, 2009). 
Furthermore, newcomer children sometimes function as language and culture brokers for their adult relatives (Marshall et al., 2016). For example, refugee youth may accompany adults to undertake financial transactions at the local and state levels because they have grasped the dominant language more quickly. Some youth have also been asked to accompany parents to medical appointments where they are made to translate medical procedures above their cognitive and developmental levels. This role reversal puts them in situations unsuitable for their familial roles and developmental levels (Marshall et al., 2016). These experiences add to the expected stressors of an adolescent navigating a new society. Goodrum et al. (2015) also studied gang involvement in immigrant populations. Multivariate analyses of this study's data revealed that racial discrimination, negative parenting, and exposure to community violence were positively associated with gang involvement, whereas peer support was negatively related to gang involvement. Given the negative correlation between peer support and gang involvement, we propose engaging refugee youth in a peer group setting. Additional best practices in counseling refugee youth include intersecting clients' experiences and environments with identifying clients' strengths, trust building, family-focused counseling, cultural competence and creativity (Marshall et al., 2016).

Counselors who lean into cultural competence continually educate themselves on multiple worldviews and pay attention to clients' values and norms (American Counseling Association, 2014). For example, American culture values independence while the average African refugee's culture values interdependence (Sue \& Sue, 2016). Subsequently, when a counselor pathologizes a refugee's cultural values, it sets the stage for ruptures in the therapeutic alliance. Counselors also pay attention to clients' perception of strengths. Research indicates that refugee clients find connection to their culture a source of strength (Marshall et al., 2016); this is a reflection of relationship with others in the area of PTG that clinicians evaluate.

\section{The PTG Model and Group Work}

For refugees who experience collective trauma, shared experiences help them develop new narratives, rumination becomes more deliberate and there is a cognitive shift which causes a schema change (Acquaye, 2017). It is through these processes that posttraumatic growth occurs for some, while others develop posttraumatic stress disorder (PTSD). As described in the PTG model (Figure 1), individuals may cycle through these processes in a non-linear way.

Clinicians using the PTG model evaluate clients' reported growth after trauma in five areas: appreciation of life; relationships with others; new possibilities in life; personal strength; and spiritual change (Calhoun \& Tedeschi, 2014). It is possible for a person to gain growth in one area while the other areas either gradually grow or possibly stagnate. Counselors pay attention to areas of growth and validate clients' progress. Even when refugee youth report growth, they may still recognize the challenges they face and yet have a positive outlook about aspects of their lives that have changed (Marshall et al., 2016).

The existing literature supports a culturally-informed group approach to help African refugee youth navigate their transition and promote post traumatic growth as they adjust to living in the US. The group model (Figure 2) is proposed as a prevention strategy to be offered in a school setting by a professional mental health counselor. The literature supports emphasizing peer support and collectively developing positive narratives in order to promote PTG in refugee youth (Acquaye, 2017; Goodrum et al., 2015). This model will not be sufficient to treat youth who have already developed PTSD, and we recommend pre- 


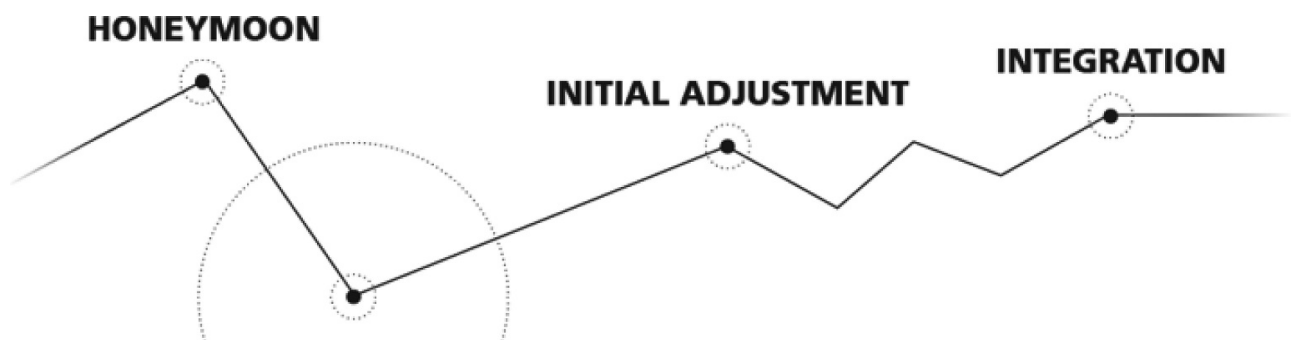

CULTURE SHOCK

Figure 2. A typical cycle of adjustment for young refugees. Adapted from the Spring Institute for Intercultural Learning "Cultural Adjustment, Mental Health, and ESL: The Refugee Experience - the roles of the teacher and ESL activities. www.springinstitute.org

screening participants to ensure that youth with clinically significant symptoms are referred to appropriate counseling supports when needed.

\section{Group Therapy Model}

\section{Collaboration between Helpers}

School counselors who have large refugee populations can contact refugee-serving agencies in their counties or cities. The first author worked with a refugee-serving agency in the Pacific Northwest and reports that some language-specific counselors and social workers, along with their interns, would visit some schools with known refugee children. During this visitation, they would spend time consulting with school counselors and offering culturally-sensitive resources that could ease some of the acculturative stressors of refugee youth. She also reports that this agency served families from specific communities with large refugee samples; the helpers would visit the school districts in those communities and offer any support to the school counselors. For example, these counselors and social workers organized a psychoeducation group exploring some challenges in adolescence for Arabic-speaking refugee youth. Another set of helpers also established a psychoeducation group addressing study habits for Pashtu-speaking high school students in another school district. School counselors should seek out similar resources in their areas. For the purpose of the group intervention described in this article, we recommend that a school-based mental health counselor would be the primary leader of the intervention, working closely with school counselors and potentially with community volunteers. Schools and mental health agencies should identify an appropriate point person within the system who can facilitate the group and seek out community resources prior to beginning.

\section{Selection}

We recommend this group for East African refugee youth living in the US. Because of the nature of the sample, care must be taken with the selection process. Even though earlier research has identified no significant differences in trauma effect based on gender (Acquaye, 
2018), most studies on refugees consistently find significant differences between gender (Powell et al., 2003; Tedeschi \& Calhoun, 2004). Inclusion criteria for this group will be (a) gender-specific - for this group under discussion, all females; (b) Age 14-18; (c) Swahili speaking African refugee youth; and (d) approximately eight to ten members (Corey et al., 2014). Finally, to make the group as homogenous as possible, we will limit the group to youth who have been in the US for two years or less and are still navigating the legal and social systems. Swahili is a common language spoken in East and South-Eastern Africa (Prins, 1961). Therefore, because participants come from these regions, we hope they will be able to express themselves in Swahili, especially for those not as confident in expressing themselves in English. This paper will use the term "group leaders" and "facilitators" interchangeably to refer to anyone leading or facilitating the group. We also use "group members" and "participants" interchangeably to refer to the adolescents who will be part of this group. If therapists want to use this paper as an example, we recommend that they assess which group will benefit most from a group like this and make their choice accordingly.

\section{Pre-Group Preparation}

Group facilitators should be trauma informed mental health counselors trained in mental health assessment and group counseling. We recommend facilitators who are culturallycompetent and trauma-informed to co-lead this group (Sue \& Sue, 2016). When possible, group leader gender should match that of the members (Pathways to Wellness, 2013). The group leader will conduct a brief pre-screening assessment to make sure each participant is a good fit and is not demonstrating any unmanaged PTSD symptoms. This could interfere with the student's ability to benefit from the group or negatively impact other group members.

Participants will be identified and invited by their school counselor. Once participants are identified, the group leader will work closely with the school counselor to find a consistent and private group meeting space at the school most participants attend. Group members will receive a brief written description of the group and will sign an informed consent before joining. Group facilitators should have the following materials available: flipcharts and markers, pens or pencils, scratch papers, journals for members, and arts and craft papers, scissors, and glue. Facilitators should check in regularly with school counselors to allow collaboration in supporting refugee youth in the school setting (American School Counselor Association, 2012; Gysbers \& Henderson, 2012).

Many cultures respond to conversations around shared meals. The curriculum used by many resettlement agencies (Pathways to Wellness, 2013) recommends providing food and drink, especially at the first session. The presence and sharing of food will likely create a comfortable atmosphere that will increase member participation. Proponents of the inclusion of food in group therapy assert that food fosters a nurturing atmosphere and enhances socialization, while allowing group members work through conflict in a nonthreatening way. The presence of food also provides a perception of warmth and safety in a respectful and accepting space (Butler \& Wintram, 1991; Lee, 1994). The sharing of food, with its impactful underpinnings in some cultures, could also be seen as a way of hindering the therapeutic process (Mishna et al., 2002). Food could be seen as hindering the therapeutic approach by preventing group members from expressing negative emotions to 
facilitators whom they see as feeding them. Additionally, while some foods may be viewed as delicacies for some tribes, other tribes may see it as taboos, thereby alienating some members. Another concern is that the presence of food may create discomfort depending on the type of food, drink, and level of acculturation of members into the dominant culture (Mishna et al., 2002). Group leaders should use discretion when deciding if they will provide food.

\section{Session 1}

At the beginning of the first group meeting, facilitators will explain the process of counseling in the US as many clients may not be familiar with this concept (Marshall et al., 2016), and support members in choosing personal goals. Leaders will explain the importance of confidentiality, role of leaders, role of members, and the duration of sessions. The three primary goals of session one are (a) to discuss ground rules; (b) clarify participant understanding of group counseling and its purpose; and (c) to introduce the posttraumatic growth model. Within this model, participants will learn about the potential for growth in these five areas: appreciation of life; relationship with others; new possibilities in life; personal strength; and spiritual change (Calhoun \& Tedeschi, 2014).

We will encourage members to introduce themselves, their country of origin, length of stay in the US, language(s) spoken, one good memory from their home country, and one favorite food from their ethnic background. When possible, group leaders can provide a flow chart of activities in the group in both English and Swahili. When discussing ground rules, group leaders will break down the concept of confidentiality with practical examples. After explaining confidentiality in therapy, a leader may provide this example: "let's say I come visit you at home and you're there with your family, I won't ask you about the trouble you shared in group that you had with another refugee from Iraq. What we say in the group stays in the group. That is the only way we can trust each other and have an open and honest group process." It is important to give multiple examples to illustrate privacy. For instance, group leaders might explain that when you are having dinner at home, you can't say, "Ma, do you know Auntie Esther's daughter, the one in my group, she has depression since she came to the US?"

Another ground rule will be treating each other with respect even when in disagreement. A third rule will be support for and openness to each other. Facilitators are encouraged to find out from group members what other rules they would want established as well. The facilitator could write these rules on the flip chart and show it at every session.

For the second objective, members will break out in pairs and discuss what they remember about the concept of group counseling and their personal goals for the group. Members will come back as a big group after 10 minutes to share what they talked about in their small groups. Group leaders may write them down on the flip chart as well.

Finally, group leaders will describe the PTG model and provide information about ways they believe each member can grow through this experience. Yalom and Leszcz (2005) identify instillation of hope as essential to the therapeutic group process. Group leaders will describe the five areas of growth that members could see in themselves and provide examples of how growth might happen after a stressful event. For example, leaders may say, "you may notice that you tend to spend more time with your little brothers or sisters now than before the war, and you tend not to be as irritated by them as previously. This 
could be growth in the relationship with others domain. Some people find that they care more about their relationships after they realize they could lose them." Group leaders will encourage members to notice change and discuss how this shows growth.

\section{Session 2}

The second session may start with an icebreaker. As an introduction, members may share their takeaway from the last group. To foster growth in the relationship with others, new possibilities in life, and appreciation of life domains, leaders may take members through the stages of resettlement. Facilitators could draw a diagram (see Figure 2) on the flip chart and explore that with group members.

Leaders will remind members that cultural shock does not have an expiration period. It is an experience that reoccurs several times over a person's life. For example, even when youth feel they have adjusted in their new culture, a marriage, birth, funeral, or even travel can throw people into cultural shock again, requiring time to adjust (Pathways to Wellness, 2013). At this stage, leaders will allow members to share their own experiences about cultural shock, as well as processes of adjusting and readjusting. With the shared experience, members could start growing in the relationship with others domain of PTG.

\section{Session 3}

The third session, like the previous, and for all subsequent sessions, starts with an icebreaker where members share their takeaway from the previous session. Along with instilling hope, the leader will also assist the group members in becoming more aware of themselves. One way to begin is by creating awareness of different roles they have played in their lives. This activity is an attempt to enhance growth in the personal strength and appreciation of life domains.

Prior to beginning the activity, leaders will give members pens or pencils, scratch paper, and their journal. Members will make a list of all the names they have been given or called throughout their life. These names may include nicknames, role names, special names or even general names like ... "The tall one", "boy", or "girl”. Members may add a positive (+) or negative (-) sign to identify the particular emotion associated with the name. Members will then choose one name on which to focus for this activity.

On the back of their paper, each member will write the name they have chosen backwards. They may then pretend it is a word in another language, ancient, real, or imaginary (Pendzik, 2008). Group leaders will encourage members to consider what this word intuitively means by its sound. Members will write a sentence to show an example of how they want their new name to be used, and then give the sentence some context by creating a story around it. During the last 10 minutes of group, participants will use their journals to reflect on their experience with this activity. Some prompts for reflection may include: Is the story that emerged from the name's reversal connected to the name's meaning in any way? What feelings come up for me as I played with the new word created from the name? Is there anything I want to share about the process of choosing the name (Pendzik, 2008)? 


\section{Session 4}

Activities in session four may take the form of psychodrama (Moreno, 2014). During this session, the larger group will be divided into smaller groups of three or four. In these smaller groups, members will be encouraged to share their materials from the previous session's task of uncovering their different names. During this session, share the different names and ultimately choose one to develop into a scene to present to the whole group. They may invite others to act in their scene in a form of psychodrama - this is an attempt to strengthen the relationship with others, new possibilities in life, and possibly spiritual change domains. For many African cultures, the giving of names is a spiritual and communal exercise (Mirzoeff, 2000). A prompt for reflecting on this session may include: "What was it like to turn a name into a story? What did you learn from talking about the names other people had chosen?"

\section{Session 5}

Session five is intended to foster growth in spiritual change and personal strength domains. The group leader should choose a familiar story that represents change, adversity, or loss. A common story such as Snow White or the Three Little Pigs could be used or a culturally relevant story such as The Enchanting Song of the Magical Bird (Fredericks, 2008) which originates in Tanzania but is known in other East African cultures. The facilitator will either read the story from the book or summarize it if the book is not present. After the telling of the story, the facilitator will explain an allegory and describe the role allegories play in stories, using examples from the story just read/told, and encourage members to find any hidden meanings from the story they just heard.

The leader will ask the group to discuss: Who is the story about? What obstacle(s) arise in the story? How do they deal with the obstacle(s)? Who or what can help them? Was the obstacle(s) overcome and will they encounter it again? Group members are thereafter encouraged to talk with a partner and think of a situation in their own life where they faced an obstacle. How did they overcome it?

Using the original story, invite 3-4 group members to act out different roles in the story. The remaining group members should try to guess the point being made by the story. Brainstorm as a group and explore take-aways from this story. Assist the group in developing their own story together about the topic of "coming to America." Help them identify something that they lost and something that they found during their transition. This session corroborates research on the use of arts-based therapy with youth survivors of traumatic experiences (Johnson \& Emunah, 2009; Mohr, 2014).

For reflection, some prompts may include: What was something new you discovered about this story? What were some of your conflicting emotions? What are some different ways we can feel about loss? The group leader will continue to model appropriate behavior and encourage appropriate risk taking, especially as it translates to action for everyday life. It is important at this stage to also remind members about confidentiality and its importance in fostering trust and feedback. The leaders may also want to provide some interpretation for patterns of behavior so that members can explore themselves more. Finally, leaders may offer insights into how one story might relate to another's story or experience. 


\section{Session 6}

This session will foster growth in personal strength and new possibilities in life domains. Activities in this session pull from theoretical works of Perls (Perls et al., 1951) and Moreno (2014). Members will be asked to create a blank mask and take on a role. Masks are especially useful when trying to externalize issues (Johnson \& Emunah, 2009). One participant will volunteer to act out the person he or she is pretending to be with their mask, allowing the rest of the group to guess. After a few members have attempted in this identification, the role player describes who he or she is pretending to be. Group leaders then allow members to create three masks that address the following - a mask that depicts a problem in your life, a spiritual guide mask that depicts personal resources to deal with the problem, and a future self-mask depicting who you would like to become (Johnson \& Emunah, 2009). The members will reflect on how their role was determined prior to arriving in the US, who has contributed to their perceived role in the US now, and who will help define their role in the future. Next, using an empty chair, members will be encouraged to address significant others in their lives who have contributed to a problem, a spiritual intervention or a personal resource (Perls et al., 1951). Using the mask connected with the aspect members are addressing, they will be allowed to express a feeling, thought, or reaction to the empty chair representing the significant other. Group leaders will then lead a discussion exploring members' reactions and feelings toward the activity.

As the group closes, leaders will remind members that they have two sessions remaining. Leaders may also inform members of the possible feelings they may experience with ending the group. Finally, this is the time when nonparticipating members are encouraged to be active participants in their own healing journey as leaders challenge them to think about the possibility of their involvement in the final sessions remaining (Corey et al., 2014).

\section{Session 7}

This session continues with the drama exercise of using masks. Members who may not have had an opportunity to share will be given their chance to act and share. In this session, leaders could include bringing out the masks and inviting members to share by acting out who they are at home, by themselves, at school, or with their friends.

Leaders will help members process how this experience felt for both volunteers or "actors" and witnesses or "audience". Follow up discussions could include the following: What mask do you wear the most? With whom do you wear it? What does it feel like to not wear a mask at all? Reflect on take-aways by writing it down in personal journals.

\section{Session 8}

The final session fosters growth in all domains of PTG. Group leaders will allow members time to remember the best gift they ever received. Leaders will encourage members to imagine this gift came in a box. On the first go-around, have each member identify what they are feeling about the gift. On the next go-around, each participant identifies what the gift meant and what it was like to receive that gift. Let the group help identify themes from feelings shared about the gifts. 
Have the group work together to create a list of gifts they would like to receive. Choose one special gift to focus on. Discuss the following questions: "If someone received this gift, how would they feel? If someone took this gift away, what parts could they take away and what parts could they not take?"

Group leaders should acknowledge that this is the final session in the group and have each member identify one gift that they have recognized in themselves through their participation. Once each member has shared, have the members take five minutes to draw their special gift in their journal. At the end of this group, members will take their journals and masks home with them if they choose.

\section{Conclusion}

Post-traumatic growth (PTG) is the occurrence of positive transformation within the life of an individual as an outcome of traumatic experiences. The PTG model illustrates how individuals who have survived traumatic experiences manage emotional distress, create new narratives and develop in five distinct domains. Various studies regarding post-traumatic growth in refugee populations demonstrate opportunities for clinical work to influence symptoms of trauma, plus common internal and external stressors related to the acculturation process. African refugee youth in particular, confront unique challenges with systemic racism in the US in addition to the initial traumatic occurrences in their country of origin. Welcoming cultural identity and expression within an educational environment, along with peer support may be utilized to mitigate the effects of risk factors including racial discrimination, negative parenting and exposure to community violence. We identified strengths within the collective nature of group work in conjunction with the PTG model, and also used psychoeducation to explore resettlement narratives.

\section{Recommendations}

This paper adds to the literature on trauma and growth, especially in adolescent youth. This paper is a combination of personal experience and conceptualization. To validate the efficacy of this curriculum, we recommend that counselors produce case studies and narrative that depict the benefit or lack of it in their unique samples. Additionally, even though this is a group module, participants could be assessed via single-case study designs to examine how their participation in such a group is contributing to psychological growth and acculturation.

Scholar practitioners who work with refugee or immigrant samples could undertake preand-posttests when this curriculum is used as an intervention. Narratives of teachers and school counselors could be coded to understand the effect of this group therapy module on students' ability to navigate the school environment - both in and out of the classroom using qualitative research methods.

\section{Notes on contributors}

Hannah E. Acquaye is assistant professor of counseling at Western Seminary. She specializes in trauma post-traumatic growth among refugee populations. Dr. Acquaye is now in Ghana working with University of Education, Winneba in their Counseling Psychology Department. 
Carol M. John is a Program Director for Carpe Mundi a non-profit in Portland, Oregon. She is a graduate of and guest lecturer for Western Seminary's counseling program.

Laurie A. Bloomquist is a counselor educator and mental health counselor in Portland, Oregon. She specializes in working with children and youth.

Nicole M. Milne is a graduate of Western Seminary in Portland, Oregon and currently works as a counselor in a community mental health setting in Washington state.

\section{ORCID}

Hannah E. Acquaye (D) http://orcid.org/0000-0003-1403-698X

\section{References}

Acquaye, H. E. (2017). PTSD, optimism, religious commitment, and growth as post-trauma trajectories: A structural equation modeling of former refugees. The Professional Counselor, 7(4), 330-348. https://doi.org/10.15241/hea.7.4.330

Acquaye, H. E. (2018). Assessing the factor structure of models for posttraumatic stress disorder symptoms in a war-related civilian sample. Counseling Outcome Research and Evaluation, 9(2), 90-101. https://doi.org/10.1080/21501378.2018.1461532

Acquaye, H. E., Mitchell, M. D., Saliba, Y., Oh, S., \& Heard, N. (2018). Optimism in trauma and growth: A path analysis of former war-related displaced persons. Journal of Pedagogical Research, 2 (1), 16-29. https://doi.org/0000-0003-1403-698X

Acquaye, H. E., Sivo, S. A., \& Jones, K. D. (2018). Religious Commitment's moderating effect on refugee trauma and growth. Counseling and Values, 63(1), 57-75. https://doi.org/10.1002/cvj.12073

American Counseling Association. (2014). ACA code of ethics. Author.

American Psychiatric Association. (2013). Diagnostic and statistical manual of mental disorders (5th ed.).

American School Counselor Association. (2012). The ASCA national model: A framework for school counseling programs (3rd ed.). Author.

Antonovsky, A. (1993). The structure and properties of the sense of coherence scale. Social Science \& Medicine, 36(6), 725-733. https://doi.org/10.1016/0277-9536(93)90033-Z

Betancourt, T. S., McBain, R., Newnham, E. A., \& Brennan, R. T. (2014). Context matters: Community characteristics and mental health among war-affected youth in Sierra Leone. Journal of Child Psychology and Psychiatry, 55(3), 217-226. https://doi.org/10.1111.jcpp. 12131

Bonanno, G. A. (2004). Loss, trauma, and human resilience: Have we underestimated the human capacity to thrive after extremely aversive events? American Psychologist, 59(1), 20-28. https://doi. org/10.1037/0003-066X.59.1.20

Butler, S., \& Wintram, C. (1991). Feminist group work. Sage Publications.

Calhoun, L. G., Cann, A., \& Tedeschi, R. G. (2010). The posttraumatic growth model: Socio-cultural considerations. In T. Weiss \& R. Berger (Eds.), Posttraumatic growth and culturally competent practice: Lessons learned from around the globe (pp. 1-14). Wiley.

Calhoun, L. G., \& Tedeschi, R. G. (2014). The foundations of posttraumatic growth: An expanded framework. In L. G. Calhoun \& R. G. Tedeschi (Eds.), Handbook of posttraumatic growth: Research and practice (pp. 1-23). Psychology Press.

Carver, C. S., \& Scheier, M. F. (2002). Optimism. In C. R. Snyder \& S. J. Lopez (Eds.), Handbook of positive psychology (pp. 231-243). Oxford University Press.

Corey, M. S., Corey, G., \& Corey, C. (2014). Groups: Process and practice (9th ed.). Brooks/Cole, Cengage Learning.

Fredericks, A. D. (2008). African legends, myths, and folktales for readers' theatre. Teachers Idea Press. 
Goodrum, N. M., Chan, W. Y., \& Latzman, R. D. (2015). Gang involvement among immigrant and refugee youth: A developmental ecological systems approach. International Journal of Developmental Science, 9(3,4), 125-134. https://doi.org/10.3233/dev-150164

Gysbers, N. C., \& Henderson, P. (2012). Developing and managing your school guidance and counseling program (5th ed.). American Counseling Association.

International Counseling and Community Services. (2015). Walking together: A mental health therapists' guide to working with refugees. Lutheran Community Services Northwest.

Jani, J. S., \& Reisch, M. (2017). Assisting the least among us: Social work's historical response to unaccompanied immigrant and refugee youth. Children and Youth Services Review, 92, 4-14. https://doi.org/10.1016/j.childyouth.2018.02.025

Johnson, D. R., \& Emunah, R. (Eds.). (2009). Current approaches in drama therapy. Charles C. Thomas Publishers.

Johnson, R. J., Hobfoll, S. E., Hall, B. J., Canetti-Nisim, D., Galea, S., \& Palmieri, P. A. (2007). Posttraumatic growth: Action and reaction. Applied Psychology, 56(3), 428-436. https://doi.org/10. 1111/j.1464-0597.2007.00296.x

Lee, J. A. B. (1994). The empowerment group approach. In F. J. Turner (Ed.), The empowerment approach to social work practice (pp. 208-261). Columbia University Press.

MacNevin, J. (2012). Learning the way: Teaching and learning with and for youth from refugee backgrounds on Prince Edward Island. Canadian Journal of Education, 35(3), 48-63.

Marshall, E. A., Butler, K., Roche, T., Cumming, J., \& Taknint, J. (2016). Refugee youth: A review of mental health counselling issues and practices. Canadian Psychology, 57(4), 308-319. https://doi. org/10.1037/cap0000068

Mirzoeff, N. (Ed.). (2000). Diaspora and visual culture: Representing Africans and Jews. Routledge.

Mishna, F., Muskat, B., \& Schemess, G. (2002). Food for thought: The use of food in group therapy with children and adolescents. International Journal of Group Psychotherapy, 52(1), 27-47. https:// doi.org/10.1521/ijgp.52.1.27.45462

Mohr, E. (2014). Posttraumatic growth in youth survivors of a disaster: An arts-based research project. Art Therapy: Journal of the American Art Therapy Association, 31(4), 155-162. https:// doi.org/10.1080/07421656.2015.963487

Moreno, J. D. (2014). Impromptu man: J. L. Moreno and the origins of psychodrama, encounter culture, and the social network. Bellevue Literary Press.

Patel, S. G., Staudenmeyer, A. H., Wickham, R., Firmender, W. M., Fields, L., \& Miller, A. B. (2017). War-exposed newcomer adolescent immigrants facing daily life stressors in the United States. International Journal of Intercultural Relations, 60(September), 120-131. https://doi.org/10.1016/j. ijintrel.2017.03.002

Pathways to Wellness. (2013). Integrating refugee health and well-being: Community adjustment support group training manual and curriculum. Lutheran Community Services North West.

Pendzik, S. (2008). Dramatic resonances: A technique of intervention in drama therapy, supervision, and training. Arts in Psychotherapy, 35(3), 217-223. https://doi.org/10.1016/j.aip.2008.02.004

Perls, F. S., Hefferline, R., \& Goodman, P. (1951). Gestalt therapy: Excitement and growth in the human personality. The Gestalt Journal Press, Inc.

Powell, S., Rosner, R., Butollo, W., Tedeschi, R. G., \& Calhoun, L. G. (2003). Posttraumatic growth after war: A study with former refugees and displaced people in Sarajevo. Journal of Clinical Psychology, 59(1), 71-82. https://doi.org/10.1002/jclp.10117

Prins, A. H. J. (1961). The Swahili-speaking peoples of Zanzibar and the East African coast (Arabs, Shirazi, and Swahili): East central Africa part XII. Routledge.

Seligman, M. E. P. (2002). Authentic happiness: Using the new positive psychology to realize your potential for lasting fulfilment. Atria Books.

Sue, D. W., \& Sue, D. (2016). Counseling the culturally diverse: Theory and practice (7th ed.). John Wiley \& Sons, Inc. 
Taku, K., \& Cann, A. (2014). Cross-national and religious relationships with posttraumatic growth: The role of individual differences and perceptions of the triggering event. Journal of Cross-cultural Psychology, 45(4), 601-617. https://doi.org/10.1177/0022022113520074

Tedeschi, R. G., \& Calhoun, L. G. (1996). The posttraumatic growth inventory: Measuring the positive legacy of trauma. Journal of Traumatic Stress, 9(3), 455-471. https://doi.org/0894-9867/ 96/0700-0455509.50/I

Tedeschi, R. G., \& Calhoun, L. G. (2004). Posttraumatic growth: Conceptual foundations and empirical evidence. Psychological Inquiry, 15(1), 1-18. https://doi.org/10.1207/s15327965pli1501_01

Woods, A. (2009). Learning to be literate: Issues of pedagogy for recently arrived refugee youth in Australia. Critical Inquiry in Language Studies, 6(1-2), 81-101. https://doi.org/10.1080/ 15427580802679468

Yalom, I. D., \& Leszcz, M. (2005). The theory and practice of group psychotherapy (5th ed.). Basic Books. 